\title{
O CONCEITO DE SIMBIOSE EM PSICANÁLISE: UMA REVISÃO DE LITERATURA
}

Daniela Sheinkman Chatelard e Aurea Chagas Cerqueira

\begin{abstract}
Daniela Sheinkman
Chatelard

Psicanalista, professora adjunta do Departamento de Psicologia Clínica do Instituto de Psicologia e do Programa de Pós-Graduação em Psicologia Clínica e Cultura da Universidade de Brasília, doutora

RESUMO: O objetivo deste trabalho foi realizar uma revisão de literatura sobre o conceito de simbiose em psicanálise e sua articulação com a psicopatologia das psicoses, em especial aquelas diagnosticadas em indivíduos do sexo masculino. O estudo enfocou a vinculação do conceito à temática das relações de objeto e percorreu algumas das principais teorias psicanalíticas. As abordagens foram agrupadas de forma a apresentarem as perspectivas das teorias clássicas, seguidas das formulações de alguns estudos contemporâneos sobre o assunto.
\end{abstract} em Filosofia (Universidade de Paris VIII)

Aurea Chagas Cerqueira Psicóloga, mestre em Psicologia Clínica (Programa de Pós-Graduação em Psicologia Clínica e Cultura da Universidade de Brasília), professora de psicologia da Universidade Paulista (Campus Brasília), membro do Instituto de Psicanálise Virgínia Leone Bicudo, da Sociedade de Psicanálise de Brasília

Palavras-chave: Simbiose, relação de objeto, psicanálise, psicoses, relação mãe-filho.

ABSTRACT: The concept of symbiosis in psychoanalysis: a literature review. The aim of this study was to conduct a review in literature on the concept of symbiosis in psychoanalysis and its relationship with psychopathology of psychoses, especially those diagnosed in males. The study focused on linking the concept to the subject of object relations, and reviewed some of the major psychoanalytic theories. The approaches were grouped in order to present the perspectives of classical theories, followed by the formulations of some contemporary studies which investigate the matter.

Keywords: Symbiosis, object relations, psychoanalysis, psychosis, mother-son relationship.

DOI - http://dx.doi.org/10.1590/S1516-14982015000200007 
O termo simbiose, proveniente dos étimos gregos sym (junto de) e bios (vida), foi originariamente empregado pelas ciências biológicas para designar uma relação funcional estreita, harmônica e produtiva entre dois organismos, os quais interagem de modo ativo visando ao proveito mútuo. A palavra foi tomada por empréstimo da biologia pela pediatra e psicanalista americana Margaret Mahler, a partir de suas pesquisas de observação da relação mãe-bebê. Posteriormente, foi reconhecida na clínica psicanalítica, estudada e modificada, em relação ao seu significado biológico original, por outros autores como Bion (1966/2007), Bleger (1967/2001) e Winnicott (1956/2000). Assim, o conceito de simbiose, que no âmbito da psicanálise se encontra inserido na fenomenologia das relações de objeto, alcançou uma posição de destaque em inúmeros estudos, sendo atualmente encontrado com maior frequência na literatura psicanalítica.

Em psicanálise, a expressão relações de objeto diz respeito às formas como se configuram as inter-relações do indivíduo com o seu mundo externo e como os objetos se organizam e se relacionam no seu mundo interno (MIJOLLA, 2005; ZIMERMAN, 2001). Alguns autores psicanalíticos, sobretudo os de língua inglesa e francesa, dedicaram especial atenção ao estudo dessa temática, dentre eles Fairbairn (1941/1962), Jacobson (1970), Klein (1946/1991) e Mahler (1975/1977).

As abordagens psicanalíticas inglesas e francesas dividem-se quanto à forma como concebem a temática das relações de objeto. Originariamente, os primeiros escritos psicanalíticos apontavam o desenvolvimento da relação de objeto como dependente das pulsões (FREUD, 1905/1996). Embora Freud abordasse a noção de objeto em sua obra ("a sombra do objeto recai sobre o ego"), referindo-se a objetos como alvos da pulsão, suas teorias enfatizavam o desenvolvimento das pulsões como determinante da constituição psíquica e as relações objetais como consequentes ou posteriores a esse desenvolvimento. Os teóricos das relações de objeto defendem o desenvolvimento da relação objetal desde os primórdios do narcisismo, numa tentativa de compreender a vida inconsciente e fantasística do indivíduo, além do circunscrito pela evolução biológica (FAIRBAIRN, 1941; KLEIN, 1946; MAHLER, 1975). Os estudos realizados por Melanie Klein sobre a temática das relações de objeto e as concepções de Margaret Mahler acerca do termo simbiose contribuíram para o estudo psicanalítico das teorias das relações de objeto e sua interação com a teoria freudiana das pulsões.

Entre os teóricos de língua inglesa, o grupo representado por Melanie Klein, Margaret Mahler e Edith Jacobson concebe a abordagem das teorias das relações de objeto em sintonia com a teoria freudiana das pulsões. O grupo representado por Ronald Fairbairn e Harry Sullivan defende que as teorias das relações de objeto são um substituto para a teoria das pulsões de Freud, e rejeita a ideia da existência de pulsões inatas. Já o grupo representado por Donald Winnicott, 
Hans Loewald e Joseph Sandler assume uma posição intermediária, ao considerar o ambiente afetivo da relação mãe-criança um elemento determinante no desenvolvimento das pulsões (MIJOLLA, 2005).

Entre os franceses, Lacan (1956/1995) concebeu a relação de objeto a partir de inspiração nas teorias freudianas, kleinianas e winnicottianas. Valorizando a importância da linguagem a que a criança foi submetida, formulou a questão do objeto em termos de perda e de falta, concebendo três modalidades da falta de objeto: a privação, a frustração e a castração. Estas modalidades são vinculadas a três ordens: o real, o imaginário e o simbólico. Da união desses elementos, Lacan estabeleceu a seguinte correspondência: privação — falta real de um objeto simbólico; frustração — falta imaginária de um objeto real; e castração — falta simbólica de um objeto imaginário.

Partindo desta breve contextualização, este artigo tem o objetivo de apresentar uma revisão de literatura sobre o conceito de simbiose em psicanálise. São abordadas algumas concepções gerais clássicas sobre o tema, particularmente as de Mahler, Bion, Winnicott e Bleger, e enfocados alguns estudos contemporâneos que investigam o fenômeno da simbiose, com destaque ao observado entre mães e filhos (do sexo masculino, com diagnóstico de psicose).

\section{CONCEPÇÕES CLÄSSICAS ACERCA DO CONCEITO DE SIMBIOSE - O TERMO SIMBIOSE NAS CONCEPÇÕES DE MARGARET MAHLER}

Nos estudos de Margaret Mahler (1975/1977), o termo simbiose encontra-se inserido como uma fase no processo de desenvolvimento psicológico normal da criança. A fase simbiótica é entendida como uma condição intrapsíquica, uma característica da vida cognitivo-afetiva primitiva, em que a diferenciação entre o eu e a mãe ainda não aconteceu, ou uma regressão ao estado de indiferenciação eu-objeto se faz presente. Tal condição pode basear-se em imagens primitivas de unidade, mesmo na ausência física da mãe. Nesses termos, para essa autora, a relação simbiótica consiste numa fase muito precoce do processo de nascimento psicológico do indivíduo.

Mahler (1975/1977) concebe que o nascimento psicológico do indivíduo se dá a partir de um processo de separação-individuação constituído por fases. Embora a autora tenha se interessado pelos primórdios da infância e abordado em sua obra o período compreendido entre o nascimento e os três primeiros meses de vida da criança, concentrou sua atenção no estudo da interação mãe-criança e no desenvolvimento infantil a partir dos quatro ou cinco meses de idade. Desta forma, ela descreveu as seguintes fases do processo de desenvolvimento psicológico:

1. Fase autística normal: refere-se às primeiras semanas de vida, quando prevalece um estado de narcisismo primário absoluto, ausência de catexia dos 
estímulos externos, processos fisiológicos e falta de consciência da existência da mãe. Segundo Mahler, esta fase tem como objetivo a aquisição do equilíbrio homeostático pelo organismo no meio extrauterino, por meio de mecanismos somatopsíquicos e fisiológicos.

2. Fase simbiótica: refere-se ao período compreendido entre o segundo ou terceiro ao quarto mês de vida da criança, marcado pelo início de uma consciência difusa do objeto que satisfaz a necessidade. Nesta fase o bebê se comporta como se ele e a mãe fossem uma unidade onipotente (fusão com a mãe); não pode diferenciar interno de externo, nem eu de não-eu. Neste momento, segundo Mahler, a criança é completamente dependente do parceiro simbiótico e a simbiose tem um significado diferente para o parceiro adulto dessa relação; ou seja, “a necessidade que a criança tem da mãe é absoluta; a necessidade que a mãe tem da criança é relativa” (1975/1977, p.62). Segundo a autora,

“A característica essencial da simbiose é a fusão somatopsíquica onipotente alucinatória ou delirante, com a representação da mãe e, em particular, o delírio de uma fronteira comum entre dois indivíduos psiquicamente separados. Este é o mecanismo para o qual o ego regride, nos casos mais severos de distúrbio da individuação e de desorganização psicótica” (p.63)

3. Fase de separação-individuação:

3.1. Primeira subfase - Diferenciação e desenvolvimento da imagem corporal: refere-se ao período compreendido entre o quinto e o nono mês de idade da criança. Nesta subfase, sua atenção, que durante a fase simbiótica era, em grande parte, dirigida para dentro, gradualmente se expande através do surgimento da atividade perceptiva dirigida para fora, durante os crescentes períodos de vigília. A criança começa a diferenciar seu corpo do corpo da mãe e a diferenciar a mãe dos "outros";

3.2. Segunda subfase — Treinamento: refere-se ao período compreendido entre o décimo e o décimo oitavo mês de vida da criança. Nesta subfase, a criança começa a se locomover livremente, explorando, de forma cada vez mais ampla, os elementos da realidade. É o momento em que a catexia que estava investida na fase simbiótica é desviada para os recursos autônomos do self e as funções do eu: locomoção, percepção e aprendizagem;

3.3. Terceira subfase — Reaproximação: refere-se ao período compreendido entre o décimo nono e o trigésimo quinto mês de vida. Nesta subfase, a criança inicia um despojamento de seu sentimento de onipotência mágica, o que provoca certa vulnerabilidade da sua autoestima. Desta forma, procura reaproximar-se de sua mãe, compartilhando com ela cada nova aquisição ou destreza; 
3.4. Quarta subfase - Consolidação da individualidade e início da constância do objeto emocional: corresponde à idade de três anos. A característica principal desta subfase é a do alcance da individualidade e da constância objetal afetiva, as quais dependem da internalização de uma imagem positiva da mãe. Somente depois que a constância objetal é alcançada é que a mãe pode ser substituída por uma imagem interna confiável. Nesta subfase também se alcança a identidade sexual.

Mahler (1975/1977) entende que o fracasso do desenvolvimento do processo de individuação faz a criança regredir para a fase simbiótica com a mãe. De acordo com a autora, a regressão à fase simbiótica pode culminar numa desorganização psicótica (psicose simbiótica), caracterizada pela manutenção delirante da indiferenciação entre o eu e o objeto.

\section{O TERMO SIMBIOSE NA OBRA DE WILFRED BION}

Para Wilfred Bion, o termo simbiose adquire um significado diferente. Em seu trabalho Atenção e interpretação (BION, 1966/2007), referindo-se à dinâmica dos vínculos que regem os relacionamentos, descreveu três formas diferentes de interação entre o que denominou continente (representado pelo símbolo @, o feminino) e contido (representado pelo símbolo $\bigcirc^{\top}$, o masculino). Para ele, os vínculos podem ser de três tipos: a) simbiótico, no qual há entrega e interdependência entre os parceiros da dupla, sem perda dos referenciais individuais, harmonia, satisfação e produtividade, com vantagens mútuas que estimulam o crescimento mental de ambos; b) comensal, no qual há acordos implícitos de convivência, com restrição da vida compartilhada, indiferença, formalismo e abolição de confrontos por receio de reações violentas; e c) parasítico, no qual o hospedeiro é idealizado por identificação com um objeto onipotente, o hóspede liga-se a ele como se fosse um apêndice, e há mútua destrutividade.

Estreitamente relacionado a essa dinâmica dos vínculos está o fato de que Bion considerava os aspectos psicóticos componentes normais do eu, atribuindo-lhes a denominação parte psicótica da personalidade. Além disso, concebia o aparelho psíquico composto por duas funções: a função alfa (a), correspondente ao fenômeno, e a função beta (b), correspondente ao número, à coisa em si, à ideia. A função alfa preservaria o sujeito do estado psicótico e a função beta o desprotegeria, num processo permanente de intercâmbio entre essas duas funções, ao longo da vida do sujeito (ROUDINESCO, 1998).

\section{A PERSPECTIVA DE DONALD WINNICOTT}

Donald Winnicott (1956/2000), ao discutir a questão do relacionamento mãe-bebê em sua etapa inicial, a partir de contribuições de Anna Freud, parece 
rejeitar o uso do termo simbiose, como expresso no artigo "A preocupação materna primária”:

“Acredito que esses vários conceitos e noções deveriam ser reunidos num conjunto, e que o estudo da mãe deveria ser trazido para fora do campo puramente biológico. O termo simbiose não nos leva mais longe que à comparação entre o relacionamento da mãe e do bebê com outros exemplos da vida animal e vegetal — a interdependência física. As palavras equilíbrio homeostático evitam certos aspectos mais sutis que surgem ao nosso olhar, quando observamos esse relacionamento com a atenção que lhe é devida" (p.400)

Entretanto, suas formulações, com ênfase no fenômeno do equilíbrio homeostático, aproximam-se da descrição de simbiose mãe-bebê, tal como estudada por Margaret Mahler, particularmente a partir do conceito de "preocupação materna primária”, quando o estado de alerta da mãe promove uma vivência mãe-bebê muito semelhante à do meio intrauterino, com uma comunicação imediata e direta entre as partes. Nesse sentido, como apontou Winnicott, a mãe e o bebê constituem uma unidade.

Em seu artigo “O medo do colapso”, Winnicott (1963/1994) aborda, dentre outros aspectos, os estágios iniciais do crescimento emocional. Ali, afirma que ao herdar um processo de amadurecimento, o indivíduo só progride se houver um meio ambiente facilitador. Nesse processo, o bebê progride de um estado de dependência absoluta, em que ainda não separa o eu do não-eu, para um estado de independência relativa e rumo a um estado de independência.

O meio ambiente facilitador, tendo como característica principal a sustentação (holding), leva o indivíduo a um desenvolvimento integrador e à personalização e, por fim, à relação objetal. Este movimento progressivo para frente é correspondente, na concepção de Winnicott, a um movimento contrário na doença esquizofrênica.

\section{O TERMO SIMBIOSE NAS FORMULAÇÕES DE JOSÉ BLEGER}

O psiquiatra e psicanalista argentino José Bleger é considerado um dos pensadores mais originais da escola argentina de psicanálise. Seus estudos sobre os fenômenos psicóticos, aliados à profunda influência recebida de Enrique Pichon-Rivière, Ronald Fairbairn, Wilfred Bion e Melanie Klein, levaram-no a propor uma nova teoria do desenvolvimento emocional primitivo (MIJOLLA, 2005).

A exposição de seus mais importantes conceitos é encontrada na obra Simbiosis y ambiguedad, publicada em 1967. Ali, Bleger aborda pela primeira vez o tema da simbiose, orientado, mais particularmente, pelas concepções psicanalíticas kleinianas. 
Para esse autor, o tema da simbiose nos situa, desde o início do desenvolvimento da personalidade, na questão da inter-relação humana. Aprofundando-se nas teorias freudianas e kleinianas acerca do desenvolvimento psíquico primitivo, Bleger postula a ideia de uma etapa muito primitiva, prévia à posição esquizoparanoide descrita por Melanie Klein, a que ele denominou posição gliscrocárica (glischros, viscoso, e karion, núcleo). Nesse modelo, a posição gliscrocárica consiste numa etapa de indiferenciação, tendo como objeto um núcleo aglutinado, contendo angústias fusionais e defesas indiferenciadas, prévias às angústias paranoides descritas por Melanie Klein.

Bleger (1967/2001) compreende a simbiose como uma forma de dependência, uma relação narcísica de objeto, vinculada aos fenômenos de projeção e introjeção, na qual ocorre uma identificação projetiva cruzada, em que cada um dos depositários age em função dos papéis complementares do outro, e vice-versa. Na simbiose, há projeções maciças imobilizadas dentro do depositário, de tal maneira que, nesse último, boa parte do eu é alienada. Há também um déficit na personificação, no sentimento de identidade e no esquema corporal, assim como confusão entre os papéis femininos e masculinos, e um déficit na comunicação no plano simbólico, com um incremento da comunicação no plano pré-verbal. Para Bleger, a simbiose é “muda”. Sua sintomatologia só se torna evidente em casos de ameaças de sua ruptura. Segundo o autor, o controle do vínculo simbiótico pelos depositários tem por objetivo evitar que o depositário saia da relação narcísica de objeto.

Assim, nas palavras de Bleger, a simbiose consiste em:

“(...) uma estreita interdependência entre duas ou mais pessoas que se complementam para manterem controladas, imobilizadas e, em certa medida, satisfeitas, as necessidades das partes mais imaturas da personalidade, que exigem condições que se acham dissociadas da realidade e das partes mais maduras ou integradas da personalidade. Esta parte imatura e mais primitiva da personalidade foi separada do eu mais integrado e adaptado, e configura um todo de certas características que me levaram a reconhecê-lo como o núcleo aglutinado da personalidade. Esta separação deve ser rigidamente mantida porque, caso contrário, se pode produzir a desintegração psicótica” (idem, p.83)

\section{ESTUDOS CONTEMPORÂNEOS}

$\mathrm{Na}$ atualidade, alguns estudos psicanalíticos nacionais e internacionais tratam da questão da simbiose articulada com a psicossomática e a psicopatologia das psicoses (SUMMERS \& WALSH, 1977; SIGRID, 1981; CARSTAIRS, 1992; PIRES, 1999; COSTA, 2001; LISONDO, 2001; THOMÉ, 2001; BENHAIM, 2004; PÉREZ 
et al., 2005; ALCÂNTARA et al., 2007; NEME et al., 2007; SUMMERS, 2008; CORCOVIA \& RADINO, 2008; BRASIL et al., 2009; AZEVEDO \& NEME, 2009).

Summers \& Walsh (1977), Sigrid (1981), Thomé (2001) e Summers (2008) apresentaram os resultados de suas pesquisas relativas aos vínculos simbióticos nas psicopatologias severas, como a esquizofrenia. As pesquisas de Summers \& Walsh (1977), realizadas a partir da aplicação do Teste de Apercepção Temática (TAT), investigaram algumas variáveis relativas ao grau e ao tipo de simbiose no relacionamento mãe-esquizofrênico. Dentre outros aspectos, os resultados apontaram que os esquizofrênicos, assim como suas mães, percebem uma tendência de relacionamento simbiótico da díade, embora somente o vetor "mãe filho" (e não o vetor "filho mãe”) possa ser denominado simbiótico de fato. Ou seja, os dados mostraram que a mãe estabelece um vínculo muito mais estreito em relação ao esquizofrênico do que este estabelece com a mãe.

Sigrid (1981), partindo da premissa de que as psicoses em indivíduos do sexo masculino, jovens, frequentemente têm sua origem em um vínculo simbiótico não resolvido entre mãe e filho, investigou o relacionamento simbiótico como instrumento terapêutico para a promoção do processo de separação e individuação dos pares da díade e descreveu o trabalho terapêutico realizado com mães e filhos (do sexo masculino). Os resultados apontaram para uma mudança nos filhos, a partir do maior fortalecimento das barreiras psíquicas entre o self e os outros. Uma mudança nas mães ocorreu quando elas se sentiram capazes de diminuir sua necessidade de controle sobre os filhos. Nessa abordagem, o autor enfatizou a necessidade de manutenção de um processo psicoterápico de longo prazo para o filho, mesmo após essa intervenção pontual.

Thomé (2001), com base na hipótese de haver uma relação sinérgica de processos inconscientes entre mãe e filho, investigou o vínculo simbiótico entre uma mãe e seu filho jovem, com diagnóstico de esquizofrenia. Mãe e filho frequentaram sessões de tratamento psicoterápico, embora este tenha se recusado a continuar no processo em dado momento. Apesar disso, o filho apresentou melhora e começou a se responsabilizar mais pela sua vida (profissão e relacionamentos), ao mesmo tempo que a mãe passou a utilizar o espaço terapêutico para abordar suas próprias questões e seu próprio sofrimento, dando início assim ao processo de separação do filho.

Partindo do conhecimento de que a falta de diferenciação entre o self e os outros constitui um importante conceito para a compreensão da psicopatologia severa, Summers (2008) desenvolveu um sistema de pontuação, para apuração dos resultados do TAT. O instrumento mensura o grau de diferenciação dos relacionamentos do sujeito com os outros. A partir das histórias contadas pelos sujeitos no TAT, as díades são avaliadas em função da presença ou ausência de vários constructos, cada um dos quais sendo um elemento do vínculo simbiótico. 
Dessa forma, o pesquisador pode verificar o modo específico pelo qual o sujeito não se diferencia dos demais. As pontuações podem ser interpretadas ao nível da díade ou de forma global. Cada díade é definida por uma combinação de gênero e geração. Assim, o investigador pode obter os resultados nas seguintes díades: mulher idosa-mulher jovem; mulher idosa-homem jovem; homem idoso-mulher jovem; homem idoso-homem jovem e homem idoso-mulher idosa. Todos os resultados são somados para se chegar à pontuação total de simbiose. O instrumento também apresenta a fundamentação teórica do sistema de pontuação, as definições das variáveis, os resultados dos testes de fidedignidade e validade e o modo de utilização do sistema.

Carstairs (1992) realizou um estudo baseado nas teorias do desenvolvimento primitivo de Melanie Klein e Margareth Mahler. Nesse estudo, focalizou a fase do desenvolvimento que Klein chamou de posição esquizoparanoide e Mahler chamou de simbiótica. Percorrendo os principais conceitos destas teorias, e evidenciando o fato de que os métodos de estudo da infância diferem significativamente entre ambas, o autor indaga se há possibilidade de reconciliação entre elas.

A partir de suas pesquisas, Carstairs (idem) apresenta algumas conclusões: Mahler, implicitamente, afirmou que as relações de objeto estão ativas desde muito cedo na infância, embora tenha negado explicitamente este fato. Klein, embora não tenha estudado o relacionamento mãe-criança por meio de rigorosa observação de díades mãe-criança — como fez Mahler —, acreditava que essa relação era crucial para o desenvolvimento de autoestima e confiança por parte da criança. Mahler acreditava em um tipo de "sentimento de unidade" com a mãe na fase simbiótica; Klein também reconheceu o vínculo estreito entre a mãe e seu bebê. A autora afirmou ainda que, nos primeiros meses, a mãe representa o mundo inteiro para a criança - portanto, o bom e o mau chegam a ela por meio da mãe. Por fim, tanto Mahler quanto Klein acreditavam que perturbações no relacionamento mãe-criança levam ao rompimento da capacidade da última para interagir com o mundo externo.

Baseando-se na experiência clínica, Pires (1999) realiza uma importante reflexão sobre o tratamento de crianças psicóticas. A autora relata algumas dificuldades inerentes a esse tratamento e alguns dos possíveis danos oriundos dessas dificuldades. Uma das dificuldades apontadas pela autora é o apego exacerbado das mães em relação as suas crianças. Nesse artigo, Pires ressalta a importância da inclusão das respectivas mães nos atendimentos clínicos, levando-se em conta sua história de vida, suas necessidades, dificuldades e possíveis resistências ao tratamento, decorrentes do sentimento de ameaça de rompimento da simbiose existente. A autora conclui que, por meio de melhor compreensão sobre o lugar e a função das mães na dinâmica psíquica dos filhos, é possível o alcance de resultados mais satisfatórios no tratamento dessas crianças. 
Lisondo (2001) realiza ampla discussão acerca de conceitos da metapsicologia freudiana e de outros importantes teóricos psicanalíticos do desenvolvimento emocional primitivo. Ali, a autora aborda o tema simbiose patológica, entendida como um transtorno narcisista, sem relação objetal, que mantém um pacto sinistro e onipotente, numa estrutura indiferenciada entre um sujeito e um objeto. Segundo a autora, na simbiose patológica a extrema dependência do sujeito à mãe e o medo decorrente diante de uma possível separação mantêm o vínculo fusional.

Costa (2001) apresenta suas reflexões acerca do mal-estar inerente à subjetividade psicótica. Dentre alguns pressupostos discutidos, está o da simbiose mãe-filho psicótico, que é concebida como engendradora da rede familiar, sendo complementares, ou apenas coadjuvantes, os outros membros da família de origem. O autor se refere ao papel "esquizofrenogênico" da mãe, tal como proposto por Frida Fromm-Reichman, e ressalta que a relação mãe-filho, nesse contexto, constitui um dos eixos sobre os quais se baseia o processo de subjetivação dos indivíduos envolvidos (mãe, filho, pai, irmãos e outros).

Benhaim (2004) e Pérez et al. (2005) investigam a relação entre o vínculo simbiótico e o mundo interno da mãe de filhos psicóticos. Visando abordar a questão da queixa materna em um caso clínico de psicose, Benhaim apresenta duas hipóteses psicopatológicas:

“1. A mãe do sujeito psicótico põe seu filho num lugar de objeto de gozo, de capricho, em seu fantasma, e não enuncia nenhuma queixa diretamente a ele... À medida que notamos uma evolução favorável à criança, a queixa mais subjetiva aparece... A criança parece mudar de lugar e de estatuto à medida que se torna objeto da queixa... De que se queixa, portanto, a mãe?

2. Do fato de que seu filho não tenha feito com que ela escapasse a seu destino, a castração. O filho não a preencheu; então, nesse tempo da desilusão que está se realizando, a mãe se queixa. A primeira pessoa castrada na dialética intrassubjetiva é a mãe. É aí que se encontra, antes de mais nada, a posição da castração" (BENHAIM 2004, p.37)

Essa autora articula essas hipóteses com a questão da ambivalência materna e complementa:

"A queixa materna supõe o reconhecimento do objeto, no caso, a criança, a experimentação de sua distância (e até mesmo de sua perda) e a recusa desse afastamento. Assim, a queixa repousa sobre o confronto do sujeito com diferença, com distância, com alteridade do objeto. Podemos dizer, ainda, com separação, isto é, o confronto com essa prova do corte simbólico com o objeto" (idem) 
Dentre outros aspectos, Benhaim (2004) conclui que a queixa materna de uma mãe de sujeito psicótico está ancorada sobre três pontos: a) a separação/ autonomia que está ocorrendo; b) o limite do domínio que gera esse distanciamento; e c) a perda da certeza do amor do objeto.

Em artigo de 2005, Pérez et al. investigam a inter-relação entre a estrutura do mundo interno da mãe e a psicopatologia da criança. Os autores relatam a experiência realizada com um grupo de sessenta mães de crianças apresentando quadros psicopatológicos graves, em comparação com um grupo de trinta mães de crianças psiquicamente saudáveis. O estudo conclui que o mundo interno da mãe desempenha um papel fundamental na construção e na manutenção da psicopatologia da criança.

Neme et al. (2007) realizam ampla revisão de literatura sobre a temática "Implicações do vínculo mãe-criança no adoecimento infantil”, partindo da hipótese de que diversas doenças infantis têm etiologias relacionadas a fatores emocionais e da constatação de que o papel do psiquismo na gênese de diferentes doenças tem sido objeto de estudo no campo da psicologia e da psicossomática psicanalítica. Os autores concluem que os resultados encontrados indicam relações entre o vínculo mãe-bebê e a emergência de algumas doenças infantis, e sugerem o incremento de pesquisas sobre o assunto à luz das transformações sociofamiliares contemporâneas.

Alcântara eta al.(2007) investigam os aspectos psicodinâmicos mais frequentes e o grau de equilíbrio psíquico em pacientes de sexo feminino e masculino com diagnóstico de narcolepsia, doença neurológica crônica caracterizada por sonolência diurna excessiva e ataques de sono. Por meio da aplicação do Teste das Relações Objetais de Phillipson (TRO), e com base no referencial teórico psicanalítico, os autores identificam como fatores predominantes no funcionamento psíquico desses indivíduos: desejos de vínculos e/ou contatos afetivos idealizados; medos relativos a perdas e/ou separações; aspectos psicóticos da personalidade e mecanismos de defesa mais característicos da posição esquizoparanoide.

Corcovia \& Radino (2008) apresentam um interessante estudo sobre a relação mãe-filho, em que o filho se torna, por inteiro, a vida de sua mãe. Nessa relação, a mãe afasta o pai e qualquer outro que a impeça de usufruir plenamente de seu filho, o qual é impedido de nascer como sujeito, sendo mantido como objeto da sensação de completude da mãe. A esse filho cabe a tarefa de ser tudo o que a mãe deseja, a razão única de sua vida e por quem ela faz sacrifícios. Partindo dessa relação, e utilizando como ponto de referência os mitos gregos de Gaia e Reia, as autoras discutem a questão da identidade feminina e de como a mulher se constitui com relação a sua sexualidade. Concluem destacando o papel da cultura e do discurso social na valorização da mulher-mãe perfeita, 
que se esforça por manter os filhos sob controle absoluto à custa da anulação das subjetividades desses.

Azevedo \& Neme (2009) investigam um caso de psoríase em uma menina de seis anos, tendo como referenciais teóricos as concepções psicanalíticas de Melanie Klein quanto ao desenvolvimento emocional primitivo e de José Bleger acerca do conceito de simbiose. O estudo demonstra que a manifestação da doença da criança está associada a uma relação simbiótica entre mãe e filha. Os autores enfatizam a importância do trabalho psicoterápico com mãe e filha em separado, pelo mesmo terapeuta, mesmo que apenas inicialmente, uma vez que se trata de uma patologia do vínculo. Nessa circunstância, concluem os autores, o terapeuta pode acolher os conteúdos psíquicos de ambas e contribuir para a abertura de um espaço para a discriminação entre o eu e o objeto e maior adaptação às realidades interna e externa de ambas as partes envolvidas.

Brasil et al. (2009), por meio da aplicação do método de Rorschach em ambos os sujeitos e dos registros das observações do processo psicoterápico da mãe, investigam a relação mãe-filho adolescente em um caso de psicose, no qual está presente o fenômeno da simbiose e dificuldades da mãe em efetuar a inserção de seu filho na escola. Os autores discutem o papel da escola e da psicoterapia no processo simbiótico e concluem que a escola e a psicoterapia podem constituir um espaço de separação (interditor) para a simbiose entre mãe e filho.

\section{CONSIDERAÇÕES FINAIS}

As abordagens pesquisadas evidenciam a importância do conceito de simbiose e as inúmeras possibilidades de explorações psicanalíticas que o assunto suscita. Esses estudos são de especial interesse para a pesquisa e a clínica psicanalíticas, pois descrevem ampla variedade de contextos nos quais o fenômeno da simbiose desempenha papel relevante no processo de constituição psíquica e de desenvolvimento dos indivíduos envolvidos.

Este estudo permite observar que as diferentes teorias e perspectivas psicanalíticas abordam o fenômeno da simbiose a partir de fundamentação nas etapas do desenvolvimento emocional primitivo, especialmente nas relações mãe-criança. Entretanto, a clínica psicanalítica nos mostra, com especial clareza, a ocorrência do fenômeno da simbiose em qualquer etapa da vida do indivíduo. Esta constatação realça a pertinência da afirmação de Freud de que o inconsciente é atemporal e de que, na base dos relacionamentos humanos, subjaz a sexualidade infantil com todos os seus desdobramentos.

O fenômeno da simbiose, tal como aqui investigado, consiste numa relação de natureza narcísica, no sentido de que cada um dos membros da díade encontra-se à mercê de sua própria história de vida, de suas próprias necessidades e an- 
gústias. Como um vínculo narcísico, impossibilitado de separar-se e de entrar em contato com as respectivas subjetividades, mantém-se, alimentando-se dos poderosos mecanismos de defesa ali presentes. Compreender essa dinâmica patológica, sobretudo na clínica, é fundamental para que possamos avançar no desenvolvimento de ações preventivas e de orientação no âmbito da saúde mental e na reavaliação de ações terapêuticas em atendimentos psicanalíticos.

Assim, esta revisão abre perspectivas importantes para o aprofundamento do tema sob o vértice psicanalítico. Os resultados obtidos pelos estudos contemporâneos consultados apontam para a pertinência do incremento de pesquisas que visem discutir a natureza e as características do fenômeno da simbiose em outros contextos e em outras patologias, em díades mãe-filha, mãe-filho, pai-filha, pai-filho, irmã-irmã, irmão-irmão e outras.

Recebido em 4/4/2011. Aprovado em 6/6/2011.

\section{REFERÊNCIAS}

AINSWORTH, M. (1969) Object relations, dependency, and attachment: a theoretical review of the infant-mother relationship. Child Development, n.40, p.969-1025.

ALCÂNTARA, C.; GRASSANO, E.; ROSSINI, S. \& REIMÃO, R. (2007) O teste das relações objetais de Phillipson (TRO) em pacientes com narcolepsia. Mudanças - Psicologia da Saúde, 15(1), p.48-58, jan-jun.

ARYAN, D. (1984) Síntesis de los aportes de Margaret Mahler. Psicoanalisis, VI(2-3), Buenos Aires: Asociación Psicoanalítica de Buenos Aires, p. $425-431$.

AZEVEDO, G. \& NEME, C. (2009) Simbiose e psoríase: um estudo psicanalítico. Boletim Academia Paulista de Psicologia, 77(02/09), p.307-321.

BENHAIM, M. (2004) A queixa materna. Estilos da Clínica, IX(16), São Paulo: USP, p.36-49.

BIANCHEDI, E. (1984) El desarrollo psíquico temprano em la obra de Melanie Klein. Psicoanalisis, VI(2-3), Buenos Aires: Asociación Psicoanalítica de Buenos Aires, p.369-377.

BION, W. R. (1966/2007) Atenção e interpretação. Rio de Janeiro: Imago.

BLEGER, J. (1967/2001) Simbiosis y ambigüedad: estudio psicoanalítico. Buenos Aires: Paidós.

BRASIL, K.; AMPARO, D.; FONTOURA, F.; WOLFF, L. \& MURELLI, L. (2009) Um psiquismo para dois na psicose: a escola e a psicoterapia como interdição. Colóquio do Lepsi do IP/FE, ano 7. São Paulo: USP.

CARSTAIRS, K. (1992) Paranoid-schizoid or symbiotic? The International Journal of Psycho-Analysis, v.73, part 1. London: University Press, p.71-85.

CORCOVIA, P. \& RADINO, G. (2008) "Os filhos de Gaia e o paraíso edípico”. Revista de Psicologia da Unesp, 7(1), p.42-54. 
CORVO, R. (2008) Diccionario de la obra de Wilfred R. Bion. Madrid: Biblioteca Nueva.

COSTA, I. I. (2001) Mal-estar, subjetividade e psicose: reflexões a partir do sistema familiar. Revista Mal-Estar e Subjetividade, 1(1), Fortaleza: Uffor, p.124-137.

CVIK, N.; ARBISER, S. \& DIMANT, S. (1984) Conceptos originales de José Bleger sobre desarrollo psíquico temprano. Psicoanalisis, VI(2-3), Buenos Aires: Asociación Psicoanalítica de Buenos Aires, p.407-414.

FAIRBAIRN, W. R. (1941/1962) Estudio psicanalítico de la personalidad. Buenos Aires: Hormé.

FREUD, S. (1905/1996) “Três ensaios sobre a teoria da sexualidade”, in Edição standard brasileira das obras psicológicas completas de Sigmund Freud. Rio de Janeiro: Imago, v.VII, p.117ss.

JACOBSON, E. (1970) Conflicto psicótico y realidad. Buenos Aires: Editorial Proteo.

KLEIN, M. (1991) Inveja e gratidão e outros trabalhos (1946-1963). Obras completas de Melanie Klein. Rio de Janeiro: Imago.

(1946) "Notas sobre alguns mecanismos esquizoides", v.III, p.17-43.

(1948) "Sobre a teoria da ansiedade e da culpa", v.III, p.44-63.

(1952) "Influências mútuas no desenvolvimento de ego e id", v.III, p. $80-84$.

(1952) "Algumas conclusões teóricas relativas à vida emocional do bebê”, v.III, p.85-118.

(1957) “Inveja e gratidão", v.III, p.205-267.

(1958) "Sobre o desenvolvimento do funcionamento mental”, v.III, p.268-279.

(1959) "Nosso mundo adulto e suas raízes na infância”, v.III, p.280-

(1960) “Uma nota sobre a depressão no esquizofrênico”, v.III, p.298304.

LACAN, J. (1956/1995) A relação de objeto. Rio de Janeiro: Zahar.

LISONDO, A. (2001) "Na simbiose patológica, uma concha autística para dois: na psicanálise, nasce o ser e a linguagem”, in GRAÑA, R. \& PIVA, A. (Orgs.). Atualidade da psicanálise de crianças: perspectivas para um novo século. São Paulo: Casa do Psicólogo.

MAHLER, M. (1967) On human symbiosis and its vicissitudes of individuation. Journal of the American Psychoanalytic Association, n.15, p.740-763. (1975/1977) O nascimento psicológico da criança: simbiose e individuação. Rio de Janeiro: Zahar.

MIJOLLA, A. (2005) Dicionário internacional de psicanálise: conceitos, noções, biografias, obras, eventos, instituições. Rio de Janeiro: Imago.

NEME, C.; DAMETO, C.; AZEVEDO, G. \& FONSECA, M. (2007) Implicações do vínculo mãe-criança no adoecimento infantil: revisão de literatura. Revista Brasileira de Medicina. São Paulo: Moreira Jr., p.162-166. PÉREZ, V.; LARAÑA, M. \& UBAGO, J. (2005) Mother's inner world and psychic pathology of the child. Anales de Psiquiatría, 21(2). Spain: Arán Ediciónes, p.55-66. 
PIRES, S. (1999) A importância do atendimento à mãe na psicose infantil. Infanto - Revista de Neuropsiquiatria da Infância e Adolescência, 7 (supl. 1), p.8-41.

RIGHETTI, D. \& SEGAL, P.(1984) La teoría de D. W. Winnicott sobre el desarrollo emocional primitivo. Psicoanalisis, VI(2-3). Buenos Aires: Asociación Psicoanalítica de Buenos Aires, p.415-424.

ROUDINESCO, E. \& PLON, M. (1998) Dicionário de psicanálise. Rio de Janeiro: Zahar.

SIGRID, K. (1981) Mothers with psychotic sons: an example of parent work in adult psychiatry. Tidsskrift for Norkk Psykologforening, 18(9). Norway: Norsk Psykologforening, p.475-480.

SOR, D. (1984) Concepción del desarrollo emocional primitive a partir de formulaciones de W. R. Bion. Psicoanalisis, VI(2-3). Buenos Aires: Asociación Psicoanalítica de Buenos Aires, p.387-392.

SUMMERS, F. (2008) “Symbiosis", in JENKINS, S. A handbook of clinical scoring systems for thematic apperceptive techniques, personality and clinical psychology. New Jersey: Lawrence Erlbaum Publishers, XV.

. \& WALSH, F. (1977) The nature of the symbiotic bond between mother and schizophrenic. American Journal of Orthopsychiatry, 47 (3). New York: Eli M. Bower, p.84-494.

THOME, A. (2001) The symbiosis between a mother and her schizophrenic son in a group therapeutic process. International Forum of Psychoanalysis, 10 (1). United Kingdom: Taylor \& Francis, p.35-40.

WINNICOTT, D. W. (1956/2000) "Preocupação materna primária”, in . Da pediatria à psicanálise: obras escolhidas. Rio de Janeiro: Imago. . (1963/1994) "O medo do colapso", in WINNICOTT, C.; SHEPHERD, R. \& DAVIS, M. (Orgs.). Explorações psicanalíticas. Porto Alegre: Artmed.

ZIMERMAN, D. E. (2001) Vocabulário contemporâneo de psicanálise. Porto Alegre: Artmed.

Daniela Sheinkman Chatelard dchatelard@gmail.com

Aurea Chagas Cerqueira acerqueira21@gmail.com 
